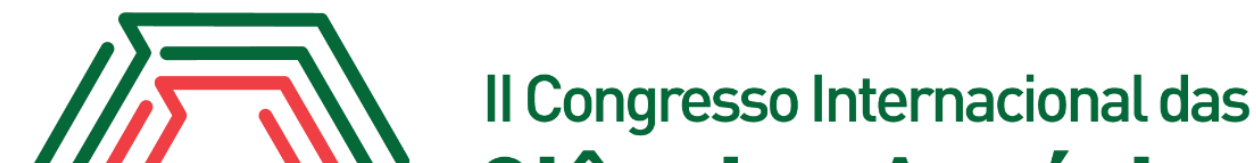 Ciências Agrárias COINTER - PDVAgro 2017
}

\section{ANÁLISE SENSORIAL DE MÉIS DE APIS MELLIFERA E MELIPONA SUBNITIDA NA REGIÃO OESTE DO RIO GRANDE DO NORTE}

\author{
Apresentação: Pôster \\ Tasyely Daylhany Freire de Lima ${ }^{1}$ Daiana da Silva Sombra ${ }^{2}$; Daniel de Oliveira Souza ${ }^{3}$; \\ Kaliane Alessandra Rodrigues de Paiva ${ }^{4}$; Patrícia de Oliveira Lima ${ }^{5}$
}

\section{Introdução}

O mel é uma substância viscosa, aromática e açucarada, produzido pelas abelhas melíferas, a partir do néctar das flores ou das secreções procedentes de partes vivas das plantas ou de excreções de insetos sugadores de plantas que ficam sobre partes vivas de plantas, que as abelhas recolhem, transformam, combinam com substâncias específicas próprias, armazenam e deixam madurar nos favos da colmeia (BRASIL, 2000).

O mel de abelha nativa (Meliponinae) é pouco conhecido em termos de composição, muitas vezes, sendo associado às características do mel das abelhas africanizadas. Assim, necessário se faz estudar esse produto, pois os hábitos das abelhas nativas se diferenciam das abelhas africanizadas, podendo alterar também a composição do produto (NOGUEIRA-NETO, 1997).

A análise sensorial é realizada em função das respostas transmitidas pelos indivíduos às várias sensações que se originam de reações fisiológicas e são resultantes de certos estímulos, gerando a interpretação das propriedades intrínsecas aos produtos. Nesta avaliação, os indivíduos, por meio dos próprios órgãos sensórios, numa percepção somato-sensorial, utilizam os sentidos da visão, olfato, audição, tato e gosto (IAL, 2008).

O objetivo do presente estudo foi analisar sensorialmente e ampliar a gama de conhecimento

\footnotetext{
${ }^{1}$ Graduanda em Zootecnia na Universidade Federal Rual do Semiárido, UFERSA, tasy freire@hotmail.com

${ }^{2}$ Pós-graduanda na Universidade Federal Rural do Semiárido

${ }^{3}$ Pós-graduando na Universidade Federal Rural do Semiárido

${ }^{4}$ Pós-graduanda na Universidade Federal Rural do Semiárido

${ }^{5}$ Docente na Universidade Federal Rural do Semiárido, UFERSA, pattlima@ufersa.edu.br
} 
sobre a preferência de méis de Apis mellifera e Melipona subnitida, produzidos na região Oeste do Rio Grande do Norte.

\section{Fundamentação Teórica}

A análise sensorial do mel de abelha é uma importante ferramenta de qualidade, que permite identificar o produto, comparar a qualidade dentro de um mesmo grupo e entre diferentes grupos, avaliar o cuidado no processamento e sua apreciação pelo consumidor final (FERREIRA et al., 2009). Segundo Arpana e Rajalaksmi (1999), o perfil sensorial de qualidade varia de acordo com a composição química, área geográfica, clima, origem botânica, abelha, manejo e armazenamento.

A cor do mel está correlacionada com a sua origem floral, podendo ser quase incolor, âmbar, escuro e pardo escuro, o processamento e armazenamento, fatores climáticos durante o fluxo do néctar e a temperatura na qual o mel amadurece na colmeia (MARCHINI et al., 2005). Logo, as características sensoriais do mel são dadas de acordo com vários fatores. Na extração e manejo do mel se deve ter muito cuidado para que não sofra contaminação por parte de resíduos, fuligens de fumaça ou armazenamento em recipientes e locais inapropriados, pois isso influenciará nas características sensoriais (ARNAUD et al., 2008).

O aroma e o sabor estão relacionados entre si e dependem de quantidades diminutas de substancias presentes no mel, derivadas de suas fontes vegetais. $\mathrm{O}$ aroma pode ser descrito como extremamente suave e agradável ou muito desagradável, como no mel de tabaco (BASTOS et al., 2002). Méis podem ser considerados doce suave ou doce ácido, dependendo do grau de açúcar presente. A viscosidade do mel depende grandemente do seu conteúdo de água e está assim ligada à sua densidade relativa, quanto menos água, mais altas a densidade e viscosidade. Todas as características sensoriais dependem do tipo de mel produzido, ou seja, do tipo de planta e abelha que os produzem (PAJUELO; VICENTE, 1996).

\section{Metodologia}

Para a realização do presente trabalho, foram utilizados méis de abelha A. mellifera coletado na Comunidade de Alagoinha, zona rural de Mossoró, Rio Grande do Norte, em maio de 2016 e abelha M. subnitida coletado na Comunidade de Valença, situada em Grossos, Rio Grande do Norte, em março de 2016 (Figura 1). A análise sensorial foi realizada no Laboratório de Análise Instrumental e Sensorial da Universidade Federal Rural do Semi-Árido. Para análise sensorial foi 
montado um painel, onde foram utilizados dois tipos de méis, sendo um de abelha M. subnitida e outro de abelha A. mellifera.

Figura 1. Méis de abelhas Apis mellifera e Melipona subnitida, produzidos nas Comunidade de Alagoinha, zona rural de Mossoró e Valença em Grossos, Rio Grande do Norte, respectivamente. A - Mel da abelha Melipona subnitida; B - Mel da abelha Apis mellifera.

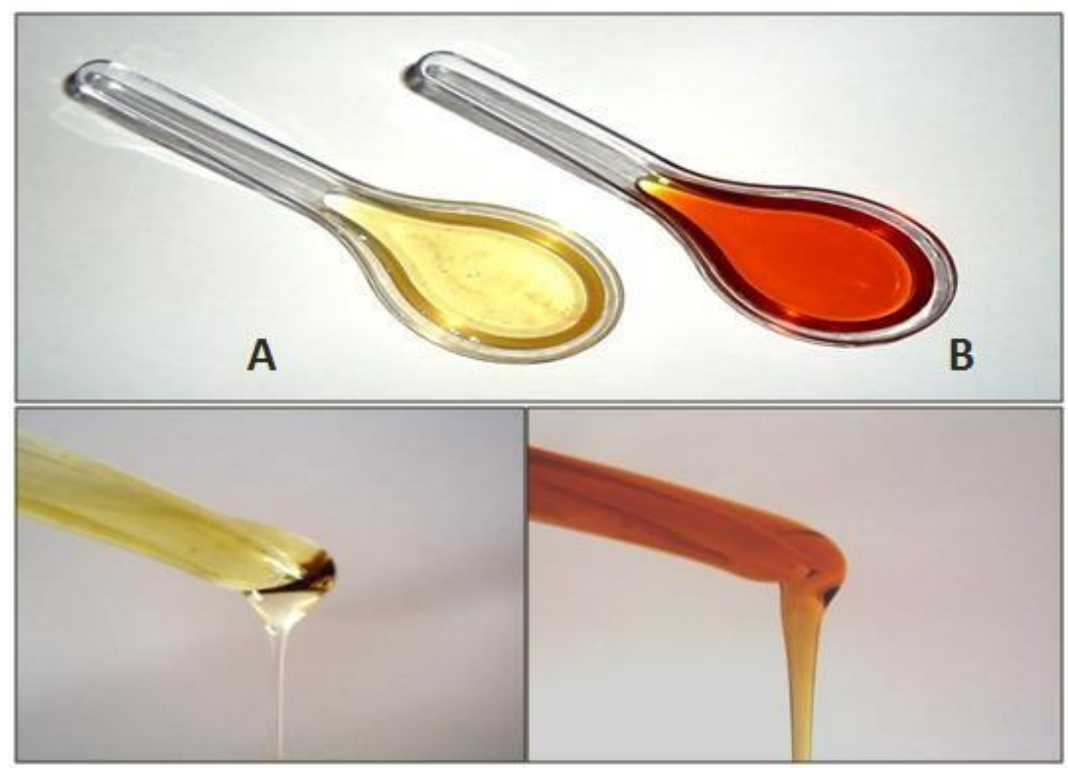

Source: Elaboration of the authors.

Foram utilizados 32 provadores não treinados com idade entre 23 e 37 anos, sendo 6 do sexo masculino e 26 do sexo feminino, os quais foram informados dos objetivos dos testes e antes da realização do painel, assinaram o Termo de Consentimento Livre e Esclarecimento. Os provadores foram orientados a iniciar o estabelecimento dos atributos pela cor, aroma, viscosidade, sabor e aceitação global, além de limpar o palato com água ou biscoito, se necessário, entre uma amostra e outra.

As amostras possuíam aproximadamente $8 \mathrm{~g}$ de mel, sendo servidas em copos descartáveis de $50 \mathrm{~mL}$ com auxílio de uma colher descartável de plástico, identificados também com número de três dígitos.

\section{Resultados e Discussões}

A Figura 1 esquematiza os resultados obtidos no painel sensorial, de acordo com as respostas obtidas. 
Figura 1. Atributos analisados na análise sensorial dos méis de Apis mellifera e Melipona subnitida.

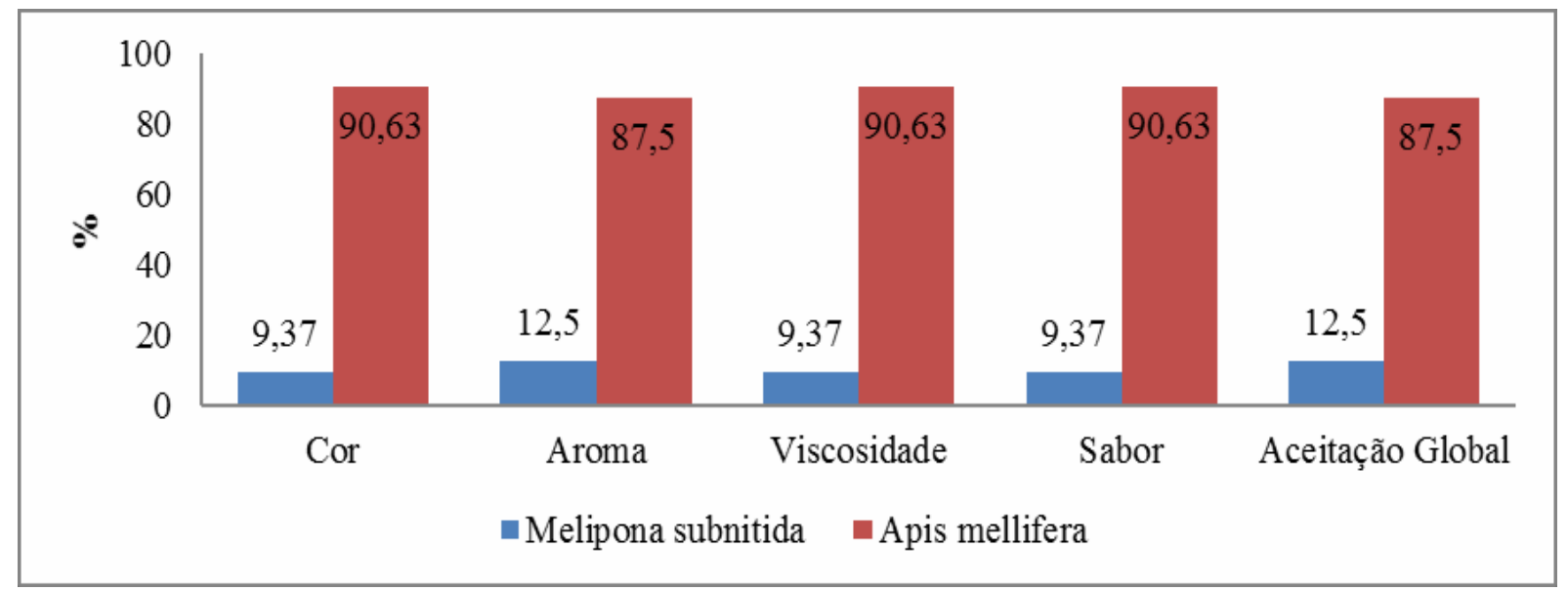

Source: Elaboration of the authors.

Para o mel da espécie $M$. subnitida os provadores descreveram o atributo cor como: cor típica de mel, cor extra clara, que preferem cor clara. Para o atributo aroma como: aroma forte, aroma típico de mel, aroma ácido, aroma cítrico, aroma azedo, aroma misturado de flor. Para o mel de A. mellifera os provadores descreveram o atributo cor como: com mais atrativa, cor característico de mel, cor mais escura, tonalidade intensa. Para o atributo aroma como: aroma característico de mel, mais adocicado, aroma mais suave, aroma mais agradável.

Quanto a ampla gama de variação aos atributos de cor e aroma encontrados nos méis, uma possível explicação seria o reflexo a influencia por diversos fatores, como origem floral, o processamento, armazenamento, fatores climáticos durante o fluxo do néctar e temperatura na qual o mel amadurece na colmeia (MARCHINI et al., 2005). A cor escura não indica qualidade inferior, ao contrário, são méis ricos em sais minerais e substâncias essenciais, sendo apreciado seu aroma.

\section{Conclusões}

O mel de abelha A. mellifera, apresentou maior aceitabilidade para todos os atributos analisados, quando comparado ao mel de abelha M. subnitida.

\section{Referências}

ASSOCIATION OF OFFICIAL ANALYTICAL CHEMISTS - AOAC. Official methods of analysis. Washington: AOAC, 1997. 1170 p.

ARNAUD, A. F.; SILVA, R. A.; ARAÚJO, L. L. S.; SANTOS JÚNIOR, R. J.; OLIVEIRA JUNIOR, D. A. Perfil sensorial de méis de Apis mellifera L., 1758 (Hymenoptera, Apidae) 
produzidos na microrregião de Catolé do Rocha - PB. Revista Verde de Agroecologia e Desenvolvimento Sustentável Grupo Verde de Agricultura Alternativa, Mossoró, v. 3, n. 4, p. 7385, dez. 2008.

ARPANA, A. R.; RAJALAKSMI, D. Honey - its characteristics, sensory aspects, and applications. Food Reviews International, Florida, v. 15, n. 4, p. 455-471, dez. 1999.

BASTOS, D. H. M.; FRANCO, M. R. B.; DA SILVA, M. A. A. P.; JANZANTTI, N. S.; MARQUES, M. O. M. Composição de voláteis e perfil de aroma e sabor de méis de eucalipto e laranja. Ciência e Tecnologia de Alimentos, Campinas, v. 2, n. 22, p. 122-129, ago. 2002.

BRASIL. Ministério da Agricultura, Pecuária e Abastecimento. Instrução Normativa $n^{\circ} 11$, de 20/10/2000. Regulamento Técnico de Identidade e Qualidade do Mel. Diário Oficial [da] República Federativa do Brasil, Brasília, 23 out. 2000. Seção 1, p. 17.

FERREIRA, E. L.; LENCIONI, C.; BENASSI, M. T.; BARTH, M. O.; BASTOS, D. H. M. Descriptive sensory analysis and acceptance of stingless bee honey. Food Science and Technology International, Caribbean, v. 15, n. 3, p. 251-258, jul. 2009.

NOGUEIRA-NETO, P. Vida e Criação de Abelhas Indígenas Sem Ferrão. São Paulo: Nogueirapis, 1997. 445p.

PAJUELO, A. G.; VICENTE, H. P. A análise sensorial nas provas de méis. São Bernardo do Campo: ABC- Gráfica Ltda, 1996. 